\title{
O PACIENTE NA PSICOTERAPIA DE GRUPO
}

\author{
Luiz Paulo de C. Bechelli ${ }^{1}$ \\ ManoelAntônio dos Santos ${ }^{2}$
}

Bechelli LPC, Santos MA. O paciente na psicoterapia de grupo. Rev Latino-am Enfermagem 2005 janeiro-fevereiro; 13(1):118-25.

O presente estudo examina o paciente na psicoterapia de grupo, abordando os fatores que Ihe proporcionam mudança no decorrer do processo e as especificidades desta modalidade terapêutica. Com base na literatura disponível e na experiência sistematizada dos autores ao longo de trinta anos de clínica grupal, são discutidas as variáveis que determinam o engajamento dos integrantes do grupo em uma relação terapêutica produtiva e bem-sucedida. Enfatiza-se a forma como o paciente assimila o processo psicoterápico e de que maneira participa no alcance de sua própria melhora.

DESCRITORES: psicoterapia de grupo; psicoterapia; saúde mental

\section{PATIENTS IN GROUP PSYCHOTHERAPY}

This study examines the patient in group psychotherapy, describing factors that provide changes during the process and the particularities of this therapeutic mode. Based on the available literature and the authors' systematic experience throughout thirty years of group therapeutic work, the variables that determine the commitment of the group members in a productive and well-succeeded therapeutic relation are discussed. It is emphasized how the patients assimilate the psychotherapeutic process and the way in which they participate in achieving their own improvement.

DESCRIPTORS: psychotherapy group; psychotherapy; mental health

\section{EL PACIENTE EN LA PSICOTERAPIA DE GRUPO}

Este estudio investiga el paciente en la psicoterapia de grupo, tratando de los factores que llevan a cambios en el transcurso del proceso y las especificidades de esta modalidad terapéutica. Basada en la literatura disponible y en la experiencia sistematizada de los autores a lo largo de treinta años de clínica grupal, son discutidas las variables que determinan el involucramiento de los integrantes del grupo en una relación terapéutica productiva y exitosa. Se destaca la forma como el paciente asimila el proceso psicoterápico y de que manera participa en el alcance de su propia mejora.

DESCRIPTORES: psicoterapia de grupo; psicoterapia; salud mental

\footnotetext{
${ }^{1}$ Psiquiatra, consultório particular, Ribeirão Preto (SP), Assistente Estrangeiro, Université Claude Bernard, Lyon, França, e-mail: bechelli@netsite.com.br; ${ }^{2}$ Psicólogo, Professor Doutor da Faculdade de Filosofia, Ciências e Letras de Ribeirão Preto da Universidade de São Paulo, e-mail: masantos@ffclrp.usp.br
} 


\section{INTRODUÇÃO}

Há 30 anos trabalhamos com psicoterapia de grupo. No decorrer desse período procuramos desenvolver um arcabouço teórico e sistematização dos procedimentos quanto à freqüência e duração das sessões, número de participantes, grupo aberto ou fechado, homogêneo ou heterogêneo, regras para manter a organização do grupo $^{(1-4)}$. Em meados da década de 70 procuramos integrar as abordagens psicodinâmica e comportamental ${ }^{(1)}$ e no início dos anos 80 , a associação de psicoterapia de grupo e individual ${ }^{(3)}$. Mais recentemente, no final dos anos 90 , começamos a voltar nossa atenção para o estudo do papel que o paciente desempenha no processo psicoterápico grupal, inclusive como agente da própria mudança ${ }^{(5)}$.

No presente estudo, é apresentado o modo como o paciente se desenvolve na psicoterapia de grupo, os fatores que the proporcionam mudança e as especificidades desta modalidade terapêutica. São discutidas as variáveis que determinam o engajamento dos integrantes do grupo em uma relação terapêutica produtiva e bemsucedida. Enfatiza-se a forma como o paciente assimila o processo psicoterápico e de que maneira participa no alcance de sua própria melhora.

\section{AS PRIMEIRAS SESSÕES E DESENVOLVIMENTO DA PSICOTERAPIA DE GRUPO}

Os clientes, sentados em círculo, na presença do terapeuta, apresentam-se pelo nome ou apelido pelo qual preferem ser chamados e as regras da terapia são apresentadas. A seguir, sem ser colocado explicitamente, no decorrer do silêncio, os participantes são convidados a expor em palavras e discutir suas preocupações. O clima criado pela situação psicoterápica favorece a auto-revelação ${ }^{(3)}$. O terapeuta e os membros do grupo tomam conhecimento de muitos fatos sobre o que se passa com cada um, sendo que pessoas que compartilham o círculo da própria intimidade podem até desconhecer esses acontecimentose mesmo não vir a saber, uma vez que o paciente não deseja revelá-los fora do contexto psicoterápico. Os integrantes do grupo exploram o material que eles próprios, geralmente e em condições normais, não analisam. A interação é livre e espontânea. Os pacientes participam verbalmente ou em silêncio, sem entraves ou censura impostos pela autoridade exterior. Desenvolvem discussão aberta, com livre associação de idéias e sem agenda preestabelecida. O tema desenvolvido pelo grupo tem alguma relevância para os participantes, suscitando pensamentos e sentimentos relacionados a experiências do presente ou do passado.

Apesar da gama de sensações e sentimentos - ansiedade, desconforto, constrangimento e pressão - que o participante possa sentir em alguma medida, ele deve sentir-se à vontade para comunicar seus pensamentos, mesmo parecendo que não tenham qualquer relação com o que está sendo discutido, assim como suas preocupações e desapontamentos com o que está se passando naquele momento. $\mathrm{Na}$ vida do grupo, todo e qualquer comportamento e evento têm um significado que deve ser avaliado. O recurso que o terapeuta dispõe para facilitar essa tarefa do grupo é a própria associação livre, sem censura das idéias verbalizadas ou das atitudes dos integrantes, bem como da maneira como emergem na malha interativa do processo grupal. Dessa forma, o paciente estará envolvido ativamente na terapia, assumindo responsabilidade com o grupo e desenvolvendo compreensão tanto consigo quanto com os outros.

Assim que o grupo amadurece, os participantes tornam-se mais envolvidos e comprometidos entre si, compartilham idéias, trocam suas experiências e oferecem espontaneamente apoio, esclarecimentos e interpretações uns aos outros. Os assuntos do grupo são tratados de forma confidencial e, à medida que os participantes desenvolvem respeito e confiança mútua, começam a assumir riscos nos temas examinados e na interação estabelecida. Decisões de grande importância devem ser discutidas no grupo. Assim que o paciente revela dados pessoais, ele se torna membro integrante do grupo. Neste momento, ele adquiriu seu "bilhete de entrada""(6).

Encontramos participantes que iniciam a terapia de forma cautelosa, permanecendo em silêncio em um primeiro momento, mas acompanhando atentamente; em uma segunda fase, tecem seus comentários a respeito do que está sendo discutido, porém evitando entrar em sua intimidade, para que posteriormente, passem a se revelar. Nesta fase, com o propósito de encorajá-lo a prosseguir em sua experiência de auto-revelação, costumamos assinalar-lhe: agora você iniciou realmente a psicoterapia.

\section{OS PARTICIPANTES E A PSICOTERAPIA DE GRUPO}

Aspecto importante e indispensável na psicoterapia de grupo é a igualdade de status dos membros. Todos são tratados do mesmo modo, com respeito e dignidade, independentemente da idade, do nível socioeconômico e cultural, talento e capacidade individual. Devese considerar que cada participante é uma fonte rica de experiência tanto para si próprio quanto para os demais.

Muitos pacientes, ao serem convidados a participar da psicoterapia de grupo, manifestam-se da seguinte forma: "Sou muito tímido; o que irei fazer num grupo se não sei me expressar?" Outros, assim revelam seus receios: "Como posso revelar a estranhos meus problemas... meu relacionamento extraconjugal?" Ou ainda: "Como irei dizer que sou homossexual?" (...) "Como posso confiar em pessoas que não conheço?" (...) "Será que esse grupo é de pessoas do meu 
nível?" (...) "Poderá um grupo de neuróticos como eu auxiliar a resolver meus problemas?" Já outros ficam logo entusiasmados com o convite e expressam seu desejo de se agregar ao grupo: "Será muito bom!" Ou ainda: "É o tipo de experiência que irá me acrescentar muito" (...) "Será um desafio para mim". De acordo com a forma de se expressar, presume-se o papel que o participante irá assumir no grupo ${ }^{(7)}$.

Para participar da terapia de grupo, assim como de outras modalidades de psicoterapia, é necessário que os pacientes tenham alguma disciplina e aceitem as regras propostas. Concomitantemente, uma condição imprescindível é que sintam motivação, e que a psicoterapia de grupo seja uma das atividades consideradas prioritárias na sua vida. Essa condição reflete o desejo de se envolver no processo terapêutico e exerce importante papel no resultado a ser obtido ${ }^{(3)}$.

\section{OS PARTICIPANTES E O PROCESSO PSICOTERÁPICO}

O paciente inicia a terapia com sua bagagem familiar e social, seu sistema de crenças, valores e seu acervo de atitudes e distorções que ocasionaram as dificuldades ou comportamentos inapropriados. É compreensível que, nas primeiras sessões, os pacientes não compreendam como a terapia irá promover mudanças. Acreditam que essa tarefa seja da responsabilidade do terapeuta que irá descobrir as causas dos sintomas ou encontrar as soluções para suas dificuldades ou problemas, imaginando que os outros membros do grupo tenham papel secundário. Além disso, não têm noção de como devam atuar para obter melhor aproveitamento. Mostram-se hesitantes e, de maneira típica, mantêm o olhar fixo no terapeuta, como se esperassem um indício ou orientação de como proceder. Questionam-se sobre qual informação seria relevante: eventos do passado ou simplesmente os relacionados àquele momento? Freqüentemente se indagam: "Devo revelar meus segredos?". Alguns consideram: "Não estou preparado para enfrentar este assunto". Em decorrência da pressão de conhecer os demais e diante da ansiedade de como proceder, geralmente descrevem fatos de sua vida e as razões pelas quais aceitaram fazer psicoterapia.

Muitos fantasiam o terapeuta como uma figura onipotente e onisciente que irá proporcionar toda ajuda, apoio, cuidado físico e emocional, de forma ilimitada, segura e constante. Transferem, assim, para outrem suas responsabilidades e dificuldades, e procuram as soluções no terapeuta ao invés de examinarem sua própria pessoa. Esta atitude ocorre particularmente nos pacientes que não tiveram experiência prévia de psicoterapia e tendem a ver seus problemas como decorrentes do ambiente ${ }^{(8)}$. Gradualmente, no curso da terapia, passam a entender que são eles próprios que irão assumir papel ativo na sua própria psicoterapia ${ }^{(9)}$, explorando, analisando, compreendendo e tentando novas soluções para os problemas.
Deve-se ressaltar, também, que as decisões a serem tomadas pela própria pessoa serão respeitadas, já que dependem da responsabilidade e autonomia de cada um, tendo em vista seus conceitos, sua visão de mundo e suas concepções sobre a vida. Nesse sentido, o cliente é o agente principal da própria mudança ${ }^{(5)}$. É muito mais o paciente e não o terapeuta que implementa o processo de mudança. O cliente é a figura central do processo terapêutico ${ }^{(9-10)}$. Aliás, com base em estudos científicos, considera-se que o paciente é responsável por cerca de $70 \%$ do resultado da terapia e que sua habilidade em empregar tudo aquilo que Ihe seja oferecido ultrapassa o que deve existir em termos de técnicas ou abordagens ${ }^{(11)}$.

O processo de transformação pessoal é complexo e determinado por diversos fatores. Para compreendê-lo conceitualmente, é preciso esquadrinhar suas raízes motivacionais. Para mudar, 0 paciente necessita estar predisposto. Essa intenção deve ter origem na própria pessoa e não nos familiares. Estes, muitas vezes, nutrem uma expectativa do que precisa ser mudado. Mas a natureza da mudança pode diferir entre as duas partes e é o próprio paciente quem irá estabelecê-la. Por outro lado, necessitará entender e se conscientizar de que o que deve ser alterado não será nas pessoas com quem convive, mas interiormente, e aceitar a responsabilidade pelas suas dificuldades. Não é o que está ao seu redor que precisa ser mudado, mas a sua própria pessoa e sua maneira de se relacionar consigo mesmo e com o mundo ao seu redor. Enquanto projetar seus problemas nos outros, dificilmente conseguirá melhorar. Com os demais participantes irá aprender que pode haver resistência à mudança, até mesmo naqueles que se mostram bem intencionados e motivados.

Convém considerar, também, que qualquer mudança que 0 paciente possa apresentar, seja numa situação em particular ou em sua vida em geral, inevitavelmente poderá repercutir, a favor ou contra, em seu meio ambiente, e encontrar incentivo ou resistência, em maior ou menor grau, nas pessoas com quem convive.

Tarefa importante dos pacientes em uma primeira fase da psicoterapia de grupo é desenvolver confiança tanto em si próprios quanto nos colegas. Nessa etapa podem encontrar-se desencorajados, dependentes e emocionalmente instáveis, ou se considerarem inadequados, sem valor e indignos de merecerem atenção. Alguns analisam cuidadosamente os riscos a que estão sujeitos com a autoexposição, para não se sentirem melindrados ou agredidos como no passado. Se as condições são seguras, se encontram coerência nas idéias e nos comportamentos, consideração, respeito, sinceridade e empatia da parte dos integrantes do grupo, passam, de forma progressiva, a revelar suas intimidades e seus sentimentos positivos, negativos ou ambivalentes. Sentindo-se mais confiantes, automaticamente aumentam a auto-estima e participam também das interações, de forma menos dependente dos outros quanto aos valores e padrões, com mais abertura e flexibilidade para vivenciar as diversas 
situações que se deparam, apresentando e manifestando suas características pessoais. As condições acima descritas são componentes básicos do processo psicoterápico ${ }^{(10,12)}$.

Ao iniciar a psicoterapia de grupo, o paciente confronta-se não só com situações de sua vida real, mas também com as dos outros membros. Dependendo da composição, o grupo pode ter um participante que tenha um significado especial ou particular para outro membro, que lhe traga recordações de experiências passadas ou de situações atuais ou que evoque seus conflitos. Nesse caso, o paciente pode passar a assumir certos riscos que normalmente evitaria: tentar novos comportamentos, compartilhar experiências, vivenciar sentimentos que normalmente procura manter à distância.

No grupo, comparações sociais constituem uma das formas para a obtenção de benefício pessoal. O paciente, ao fazer sua autoavaliação, tem oportunidade de observar seu comportamento, opiniões, sentimentos, estado emocional e seus problemas em relação aos demais, podendo rever sua identidade. Pode notar que as situações que o deixam irritado, irado ou aborrecido, não provocam a mesma reação em outros participantes; sentimentos que jamais ousou expressar são prontamente manifestados pelo colega de grupo; a idéia que fazia de si próprio e do mundo não é necessariamente como o outro pondera; sentimentos e experiências que considerava peculiar a sua pessoa são comuns em relação aos demais (reação do espelho). Independentemente do fato de essas diferenças terem tido origem na infância, em algum outro momento da vida ou, até mesmo, que o cliente não possua plena consciência de como surgiram, essas comparações podem contribuir para que tenha percepção desses aspectos e faça correção de distorções quanto a sua pessoa (eu sou diferente dos outros) que, levadas a extremo, podem atingir um nível de gravidade com sensações psicopatológicas. Comparar-se com os demais pode gerar maior conhecimento e compreensão de seus próprios sentimentos, aumento da aceitação de sua própria pessoa, bem como 0 estabelecimento de uma nova visão acerca dos demais, de si próprio e do seu mundo. No decorrer desse processo há a possibilidade de reajustar seus conceitos e se libertar do modo distorcido de se relacionar com as pessoas, reduzindo, conseqüentemente, eventual isolamento social.

Em relação à denominação reação do espelho, ressalta-se que o papel do terapeuta na psicoterapia individual tem sido freqüentemente comparado a um espelho que reflete as características do paciente, tornando-as mais visíveis aos olhos do mesmo. Mas, por outro lado, na psicoterapia de grupo, ao se ver diante de seus colegas, é como se o paciente estivesse em uma galeria de espelhos ${ }^{(13)}$.

O grupo permite ao paciente observar como os demais se comportam e o resultado decorrente dessa determinada ação. Mesmo na condição de observador, estando em silêncio, olhando e escutando com atenção, o cliente pode obter benefício da experiência da psicoterapia de grupo, sentindo-se aceito à medida que determinada situação em andamento tenha um significado particular (efeito espectador). A oportunidade de observar pode gerar aprendizado interior e estimular o paciente a testar novo comportamento.

Embora a posição de espectador possa auxiliar na mudança, a participação ativa e o envolvimento na terapia são variáveis importantes e fundamentais no resultado. Os pacientes fazem progressos, principalmente, quando expressam em palavras suas experiências e seus sentimentos íntimos ${ }^{(14)}$. Nesse sentido, foi observado que pacientes que cooperam e são mais abertos ao diálogo, na busca de maior participação, podem, mais prontamente, absorver as experiências geradas pelas operações terapêuticas e, dessa forma, se beneficiar com maior probabilidade da psicoterapia ${ }^{(15)}$.

O participante que permanece em silêncio não oferece contribuição aos demais, deixa de revelar suas experiências, de expressar seus sentimentos, receios, preocupações e idéias. É possível que omita informações, particularmente as negativas, por questões emocionais, cognitivas ou comportamentais ${ }^{(16)}$. Aesse respeito, tomando por base estudos realizados no âmbito da psicoterapia individual ${ }^{(17-20)}$, os seguintes exemplos são considerados: 1 . sentir-se assustado ou ansioso na sessão; 2. não conseguir expressar os sentimentos de forma articulada ou organizada; 3. receio de expressar sentimentos negativos, criticar, desafiar, ofender o terapeuta ou os colegas e, conseqüentemente, colocar em risco o relacionamento com o grupo como um todo e então ser rejeitado ou discriminado; 4. sentir-se diferente do terapeuta ou dos colegas; 5 . considerar que o terapeuta e/ou 0 grupo não conseguem compreendê-lo ou que seriam incapazes de ajudá-lo em determinado problema; 6. considerar, por percepção realista ou não, que seus valores pessoais são muito diferentes dos demais; 7. sentir-se inseguro ou envergonhado sobre algum aspecto pessoal ou de sua história: abuso sexual na infância, problemas ou segredos sexuais, uso de droga e/ou álcool, sofrimento/doença mental, insucesso em determinada situação; 8. supor que o terapeuta ou os colegas não suportariam o que teria a revelar, com possibilidade de causar impressão desfavorável sobre sua pessoa; 9 . não se sentir capaz e preparado para lidar com o que teria a revelar; 10. receio de que a revelação de determinado acontecimento viesse a indicar que está fazendo pouco progresso, podendo com isso desagradar e decepcionar as expectativas do terapeuta e dos colegas; 11. considerar que os colegas não se interessariam pelo seu problema ou que determinado assunto seria inapropriado; 12. alienação interpessoal; 13. dificuldade no relacionamento interpessoal; 14. não se sentir motivado em revelar o segredo; 16 . sentir-se leal a outra pessoa e não desejar envolvê-la.

Não se pode deixar de considerar o quanto possa ser desconfortável, embaraçoso e, até mesmo, doloroso revelar dados íntimos. Estudos indicam que cerca de $50 \%$ dos clientes em psicoterapia 
individual guardam segredos dos terapeutas ${ }^{(17,19)}$. Deve-se considerar a necessidade de respeitar os limites de cada um. O cliente deverá se resguardar até o momento em que se sente preparado para revelar segredos relativos aos seus aspectos que considera negativos e ser capaz de lidar com o impacto que eventualmente possa causar, por exemplo, desaprovação, rejeição, humilhação ou isolamento por parte dos colegas de grupo. A autenticidade e a revelação podem ser contraproducentes e ocasionar conseqüências negativas ${ }^{(21)}$. Aempatia do terapeuta e dos participantes do grupo, a coesão do grupo, assim como a aceitação e o respeito são fundamentais nesse processo. A aceitação encerra receptividade e interesse genuíno por aquilo que está sendo colocado, e valoriza a contribuição, sem rejeição e julgamento, independentemente do conteúdo expressado. Isto, porém, não quer dizer que se esteja de acordo com o conteúdo do que foi dito. Como resultado, o paciente gradualmente se sente seguro para explorar, enfrentar e refletir sobre seus aspectos íntimos que até então eram ameaçadores ou muito vergonhosos.

À medida que o cliente consegue deixar emergir gradualmente seus sentimentos profundos, torna-se necessário que 0 terapeuta e os participantes do grupo acompanhem essa experiência sem indignação, pois esse processo oferece alívio e conforto ao paciente, por se sentir compreendido diante de suas dificuldades e emoções dolorosas. A mudança e o crescimento tornam-se possíveis quando a pessoa consegue se aceitar como realmente é. Ao mesmo tempo, a ausência de julgamento externo estimula o cliente a desenvolver maior independência e responsabilidade, não sendo o que os outros pensam ou esperam, mas alicerçando-se na própria experiência vivida como a base principal para escolhas e decisões. Convém destacar, também, que a empatia é considerada um ingrediente ativo de mudança que facilita o processo cognitivo (compreender o significado e reorganizar conceitos, a visão de si próprio, das pessoas e do mundo) e o ajustamento emocional do cliente ${ }^{(22)}$. Além disso, pesquisas indicam associação positiva entre empatia e resultado, sendo considerada componente básico e relevante nas psicoterapias ${ }^{(23)}$.

Da mesma forma que se passa na sessão individual ${ }^{(17)}$, no grupo o paciente pode deixar de compartilhar seus pensamentos e sentimentos decorrentes de eventos que se sucedem no transcorrer da sessão: o que foi narrado por um colega, o comportamento ou reação de outro, assim como a intervenção do terapeuta. Aparentemente se mostra cooperador, atencioso e cortês, mas, interiormente, está se questionando e até mesmo vivenciando ressentimentos em relação ao terapeuta ou a um dos colegas; sente-se relutante em revelar suas reações negativas que poderão até ferir a outra pessoa, considera que não é lugar para desafios ou que é infantilidade expressar críticas.

O paciente que oculta dados significantes e deixa de expressar as emoções vivenciadas no decorrer das sessões está fadado a tornar-se menos envolvido no processo psicoterápico, a obter pouca satisfação e a não se beneficiar da experiência que se propõe ${ }^{(16,24)}$. Com atuação restrita fica privado de feedback e assim, não se dá oportunidade de avaliar seu comportamento e emoções. Perde ocasião favorável de esclarecimento de seus sentimentos que pode trazer insights significativos e mudança psicológica em potencial. Portanto, muitas circunstâncias favoráveis para ganho pessoal são perdidas, correndo-se o risco, ainda, de ficar mergulhado em fantasias sobre o que aconteceria com aquilo que gostaria de ter contado, mas não foi capaz. Todo comportamento, verbal ou não-verbal, tem seu efeito. A conseqüência ocorre na forma de resposta: direta e explícita, ou indireta e encoberta. Escutando o que as pessoas têm a lhe dizer ou observando como elas reagem frente ao que revelou, o paciente pode aprender algo sobre o impacto de sua pessoa nos outros, como foi recebido e percebido pelos demais.

A respeito do feedback, nem sempre fica muito claro como fornecê-lo. É considerado uma resposta, verbal ou não-verbal, direta ou indireta, que pode ser utilizada como uma informação a ser tomada para orientar uma ação futura ${ }^{(25)}$. O feedback que mais se aproveita é aquele em que um participante responde: "quando você disse ou fez aquilo, eu senti..." Corresponde a uma informação sincera e não a uma mera opinião ou especulação; encerra um componente emocional e, ao mesmo tempo, uma revelação pessoal. Nesta linha de pensamento, chama-se a atenção para o fato de que o feedback "eu gosto muito de você" tem muito mais impacto e valor do que "você é uma pessoa muito agradável". A observação de determinado membro do grupo: "eu estou tendo dificuldade para compreender o que você está dizendo" é preferível a: "o que você está descrevendo não está muito claro"(26). De fato, o primeiro enunciado informa ao outro como ele está sendo percebido e coloca a responsabilidade para avaliação e mudança em sua pessoa. Ressalta-se, também, a importância de fazer as observações empregando o pronome pessoal na primeira pessoa do singular: "eu"(27). Essa condição revela 0 interior do participante, aponta para sua subjetividade e instiga a sua responsabilidade, além de convidar os demais a se tornarem mais abertos e menos defensivos ao receber a comunicação. Evita que as colocações sejam impessoais, por exemplo, "os homens", "as mulheres", "as pessoas", acham ou pensam desta ou daquela forma.

O feedback torna-se, também, mais útil quando apresenta significado claro, compreensível e correlacionado com o assunto, e quando é transmitido de forma simples, sem jargão técnico, sem juízo crítico e sem conteúdo pejorativo. Dessa forma, o participante do grupo poderá avaliar livremente as informações recebidas, fazer as correlações necessárias e assumir a responsabilidade em suas reflexões. O feedback pode ser oferecido de um participante para outro, mas para ser aceito é preciso que seja dado no momento certo e que encontre o participante aberto e pronto para recebê-lo. 
No grupo, à medida que se sente mais seguro, o paciente pode tentar esboçar novo comportamento, expressar sentimentos que não faziam parte de seu repertório e observar o resultado dessa nova experiência em si próprio e nos outros. Nisso consiste, em linhas gerais, o conceito de experiência emocional corretiva ${ }^{(28)}$.

Sob determinadas condições do grupo (por exemplo, presença de um clima de confiança e segurança) o participante pode se comportar ou se expressar de uma forma que habitualmente evitaria devido à censura que impunha a si próprio. Ao tomar conhecimento de que os outros colegas admitem também sentimentos e impulsos similares, é possível que possa sentir alívio ou redução da sensação de culpa que acarretava, inclusive, inibição em muitos aspectos de sua vida. Quando o feedback demonstra que as conseqüências temidas não ocorrem, ele realiza uma experiência emocional corretiva. O paciente corrige idéias que, durante muito tempo, supunha que fossem verdadeiras, como a de que suas ações trariam conseqüências catastróficas. Por outro lado, se não testa seus temores, a pessoa permanece reprimida e inibida em seu potencial de adaptação à realidade.

Quando um participante se revela e acontece de não se sentir compreendido pelos colegas, poderá mesmo assim obter benefício, desde que se proponha a reavaliar suas idéias, emoções e forma de apresentá-las, ocorrendo efeito elucidativo para sua pessoa. Naturalmente esse processo se torna mais viável na proporção da intensidade da coesão do grupo.

Muitos dos benefícios obtidos a partir da comparação social, do feedback e da avaliação das preocupações e sentimentos ocorrem independentemente do auxílio direto do terapeuta, embora este possa, muitas vezes, intervir e assegurar que o paciente esteja dando a devida atenção e beneficiando de uma situação particular e relevante.

A tentativa inicial dos participantes é desenvolver um padrão de relacionamento dependente com o terapeuta. Embora possa ocorrer, é muito importante que gradualmente progridam e adquiram autonomia. É necessário que o paciente seja capaz e queira assumir a responsabilidade por sua participação no grupo. Precisa ter a noção de que é agente de seu próprio destino e não meramente vítima de fatores biológicos, familiares ou sociais ${ }^{(5)}$. Cada um é responsável pela maneira que interpreta e responde aos acontecimentos. Para obter benefício e progredir, o participante necessita estar aberto à interação com os demais membros do grupo e às modificações necessárias em sua maneira de ver a si próprio e o mundo. O participante deve usar sua capacidade de avaliação e decidir o que de importante deve ser mantido e o que necessita ser mudado ou abandonado, para corrigir suas deficiências e poder enfrentar, de forma apropriada, as circunstâncias da vida ${ }^{(29)}$.

A prioridade dos assuntos a serem discutidos é da competência dos integrantes do grupo, sendo, portanto, responsáveis pelos temas que escolhem. Entretanto, muitas vezes, determinados pacientes, sem a devida noção da atuação na terapia, desviam a atenção de seus aspectos intra e interpessoais contando histórias com conteúdos e preocupações irrelevantes aos objetivos da psicoterapia. Necessitam de intervenção de caráter educativo, de preferência dos próprios colegas, para direcionamento e compreensão do que devem apresentar e que seja benéfico a todos e a si próprios. Em contrapartida, há situações em que os participantes em conjunto se engajam numa conversa trivial, como se evitassem indagações e análise de fatos mais relevantes e, conseqüentemente, conflito ou disputa sobre as respostas. A esse respeito, Bion teceu o seguinte comentário: qualquer pessoa não acostumada com psicoterapia de grupo ficaria surpresa ao observar um grupo, composto por participantes supostamente inteligentes, desenvolver discussão tão limitada e agindo como se estivessem se satisfazendo emocionalmente. Denominou tal comportamento de suposto básico de "esquiva e luta", ou seja, para se defenderem da ansiedade persecutória os membros do grupo se engajam na tarefa de lutar ou escapar do perigo. Para ganhar segurança e preservar o grupo, os participantes sacrificam as necessidades individuais e a tarefa de autoavaliação ${ }^{(30)}$

Atitude não produtiva e não recomendável aos participantes é se engajarem numa tarefa em vão, tentando auxiliar o colega que se encontra em um impasse e impotente diante de um problema, estimulando-o e propondo possíveis alternativas ou soluções. Cada um deve realizar seu próprio trabalho psicoterápico, inclusive avaliar suas reações emocionais decorrentes dos acontecimentos no grupo.

No transcorrer das sessões, o paciente tem oportunidade de observar a melhora conquistada por seus colegas que obtiveram autoconhecimento, fruto do próprio esforço, em um grau que thes possibilitou assumirem atitudes positivas à luz da nova orientação que desenvolveram. Por outro lado, há momentos em que um deles regride e piora. Nesse caso, aprende que tal fato pode ocorrer, que não é motivo de desmoralização e tampouco de insucesso. Os clientes necessitam saber que não estão isentos de futuros problemas. A psicoterapia não confere imunidade a ninguém contra a possibilidade de emergência de uma nova crise, não previne necessariamente uma recaída diante de uma nova exposição a situações estressoras, nem oferece garantias de que no futuro o indivíduo sempre responderá de maneira adaptativa às adversidades e infortúnios.

No grupo, o paciente não se apresenta somente por aquilo que descreve e revela sobre sua pessoa e sua vida, mas também pela forma de se vestir, postura, comportamento não-verbal, local onde se senta (por exemplo, em um canto fora do círculo do grupo), se chega atrasado, como entra na sala (com respeito ou fazendo barulho), maneira de interagir, tom de voz (confiante, imperioso, insinuante, intimidado, etc.), o tema que escolhe e prefere discutir, etc.

No decorrer da psicoterapia e tendo já desenvolvido 
amadurecimento, o paciente reconhece o terapeuta como autoridade que, em um primeiro momento, foi fonte de esperança e, durante 0 processo terapêutico, elemento importante para seu progresso, porém não o considerando mais dotado de poderes mágicos como o concebia inicialmente. Passa a compreender, também, que todo exame interior é para seu próprio benefício e não para informar o terapeuta, e que a intervenção de mudança reside em sua pessoa, sendo responsável pelo conteúdo, aplicação e resultado da psicoterapia (princípio do livrearbítrio).

\section{CONSIDERAÇÕES FINAIS}

O ser humano desenvolve-se e existe através da interação com os outros. Nesse sentido, os pacientes descobrem na terapia de

\section{REFERÊNCIAS BIBLIOGRÁFICAS}

1. Hetem G, Bechelli LPC. Résultats de la thérapie de groupe d' orientation comportementale et analytique en 151 cas suivis jusqu' à > 24 mois. Psychologie Médicale. 1981; 13:91-6.

2. Bechelli LPC. Terapia de grupo em consultório. J Bras Psiquiatr. 1988; 37:251-5.

3. Bechelli LPC, Santos MA. Psicoterapia de Grupo. Noções Básicas. Ribeirão Preto: Editora Legis Summa; 2001.

4. Bechelli LPC, Santos MA. Psicoterapia de grupo: como surgiu e evoluiu. Rev Latino-am Enfermagem 2004 março-abril; 12(2):242-9.

5. Bechelli LPC, Santos MA. Psicoterapia de grupo e considerações sobre o paciente como agente da própria mudança. Rev Latino-am Enfermagem 2002 maio-junho; 10(3):383-91.

6. Rosenbaum M, Lakin M, Roback HB. Psychotherapy in groups. In: Freedheim DK, organizer. History of Psychotherapy. A Century of Change. Washington: American Psychological Association; 1992. p. 695-724.

7. Kadis AL, Krasner JD, Winick C, Foulkes SH. A Practicum of Group Psychotherapy. New York: Hoeber Medical Division Harper \& Row; 1963.

8. Yalom ID. A study of group dropouts. Arch Gen Psychiatry. 1966; 14:393-414.

9. Rank O. Will Therapy. New York: Norton; 1978.

10. Raskin NJ, Rogers CR. Person-centered therapy. In: Corsini RJ, Wedding D, organizer. Current Psychotherapies. $6^{\text {th }}$ ed. Itasca (Minn): F.E. Peacock Publishers; 2000. p. 133-67.

11. Tallman $\mathrm{K}$, BohartAC. The client as a common factor: clients as selfhealers. In: Hubble MA, Duncan BL, Miller SD, organizer. The Heart \& Soul of Change. What Works in Therapy. Washington: American Psychological Association; 1999. p. 91-131.

12. Rogers CR. The necessary and sufficient conditions of therapeutic personality change. J Couns Psychol. 1957; 21:95-103.

13. Grotjahn M. The process of maturation in group psychotherapy and in the group therapist. Psychiatry. 1950; 13:63-7.

14. BohartAC. The person-centered psychotherapies. In: GurmanAS, Messer SB, organizer. Essential Psychotherapies. Theory and Practice. New York: The Guilford Press; 1995. p. 85-127. grupo a possibilidade de lançar mão do relacionamento para desenvolvimento pessoal, crescimento e mudança ${ }^{(31)}$. Pode-se aqui incluir a criatividade e a inovação que envolvem a condição de estar aberto à experiência e ao novo, sem receio do desconhecido, mantendo uma atitude de espontaneidade, expressividade e flexibilidade, além da capacidade de elaborar e integrar o oposto. Quanto à flexibilidade, convém destacar a condição de aceitar conflitos e tensões que resultam de polaridade, tolerar inconsistências e contradições sem fragmentar ou enfraquecer a coesão do ego. Todas as formas de criatividade se desenvolvem por um desencadeamento de atividades, combinando e reestruturando experiências do passado em novos padrões que venham a satisfazer a pessoa ${ }^{(32)}$. Em relação ao crescimento e interação interpessoal, o indivíduo tem a possibilidade de se tornar mais espontâneo e natural, amistoso, objetivo e realista, mostrando-se menos dependente das pessoas.

15. Orlinsky DE, Grawe K, Parks BK. Process and outcome in psychotherapy: noch einmal. In: Bergin AE, Garfield SL, organizer. Handbook of Psychotherapy and Behavior Change. $4^{\text {rd }}$ ed. New York: John Wiley; 1994. p. 270-376.

16. Regan AM, Hill CE. Investigation of what clients and counselors do not say in brief therapy. J Couns Psychol. 1992; 39:240-6.

17. Hill CE, Thompson BJ, Cogar MC, Denmann III DW. Beneath the surface of long-term therapy: therapist and client report of their own and each other's covert processes. J Couns Psychol. 1993; 40:278-87. 18. Rennie DL. Client's deference in psychotherapy. J Couns Psychol. 1994; 41:427-37.

19. Kelly AE. Client's secret keeping in outpatient therapy. J Couns Psychol. 1998; 45:50-7.

20. Hill CE, Gelso CJ, Mohr JJ. Client concealment and self-presentation in therapy: comment on Kelly. Psychol Bull. 2000; 126:495-500.

21. Kelly AE, Mckillop KJ. Consequences of revealing personal secrets. Psychol Bull. 1996; 120:450-65.

22. Watson JC. Re-visioning empathy. In: Cain DJ, organizator. Humanistic Psychotherapies. Handbook of Research and Practice. Washington: American Psychological Association; 2001. p. 445-71.

23. Sachse R, Elliot R. Process-outcome research on humanistic therapy variables. In: Cain DJ, Seeman J, organizadores. Humanistic Psychotherapies. Handbook of Research and Practice. Washington: American Psychological Association; 2001. p. 83-115.

24. Wright TL, Ingraham LJ, Chemtob HJ, Perez-Arce P. Satisfaction and things not said. Clinical tools for group therapists. Small Group Behav. 1985; 16:565-72.

25. Whitaker DS. Using Groups to Help People. $2^{\text {nd }}$ ed. East Sussex (UK): Brunner-Routledge; 2001.

26. Rothkes S. The role of interpersonal feedback in group psychotherapy. Int J Group Psychother. 1986; 36:225-40.

27. Yalom ID, Vinogradov S. Interpersonal group psychotherapy. In: Kaplan HI, Sadock BJ, organizadores. Comprehensive Group Psychotherapy. $3^{\text {rd }}$ ed. Baltimore: Williams \& Wilkins; 1993. p. 185-95. 28. Alexander $F$. The principle of corrective emotional experience. In Alexander F, French TM, organizer. Psychoanalytic Therapy: Principles and Application. New York: Ronald Press; 1946. p. 66-70. 29. Ford DH, Urban HB. Contemporary Models of Psychotherapy. A Comparative Analysis. $2^{\text {nd }}$ ed. New York: John Wiley; 1998. 
30. Bion WR. Experience in Group and Other Papers. London: Routledge; 1961.

31. Rogers CR. Tornar-se Pessoa. São Paulo: Martins Fontes; 2001.

32. Hallman RJ. The necessary and sufficient conditions of creativity. In: Sutich AJ, Vich MA, organizer. Readings in Humanistic Psychology. New York: Free Press; 1969. p. 217-35. 